\title{
The Immunology of Buruli Ulcer
}

\author{
João Fevereiro, Alexandra G. Fraga, and Jorge Pedrosa
}

Buruli ulcer (BU) represents a unique human mycobacteriosis. Caused by Mycobacterium ulcerans, the disease spectrum is dominated by the activity of mycolactone, a dermanecrotic toxin that has shown the ability to interfere with the immune response. This poses an additional difficulty to the understanding of the immunological determinants for the outcome of infection, a fundamental step to develop better preventive or curative strategies. In this chapter, the immune response against $M$. ulcerans is reviewed, both with a series of clinical observations and experimental infection models and going through several other lines of evidence, including epidemiological and genetic studies. This holistic approach is expected to shed further light on the intriguing pathophysiology of this disease and help guide future research efforts.

\section{Buruli Ulcer: The First Histological Observations of a Necrotic Track}

Mycobacterium ulcerans has always been a distinct pathogen among mycobacteria. The classical clinical description of M. ulcerans infection, Buruli ulcer (BU), reports a lesion that usually begins as an indurated subcutaneous papule which slowly ulcerates, presenting as an ulcer with undermined edges [1-3]. Typical skin biopsies reveal epidermal destruction concurring with areas of hyperplasia and, in the deeper layers of the skin, a widespread panniculitis with many thrombotic capillaries and in some cases calcification of fat cells [1,3-6]. In the necrotic core, a large number of bacteria are usually present in the extracellular space amidst apoptotic cell debris,

J. Fevereiro $\cdot$ A. G. Fraga $\cdot$ J. Pedrosa $(\square)$

Life and Health Sciences Research Institute (ICVS), School of Medicine, University of Minho, Braga, Portugal

ICVS/3B's—PT Government Associate Laboratory, Braga, Portugal

e-mail: id5937@alunos.uminho.pt; afraga@med.uminho.pt; jpedrosa@med.uminho.pt 
sometimes surrounded by a belt of scattered neutrophils and macrophages with intracellular bacilli, as well as T cells and foci of B cells [1, 4, 7-10]. As such, suspicions early arose of BU pathology being dominated by an exotoxin that would diffuse and destroy the surrounding tissues [4, 11].

Indeed, purified in 1999, a polyketide-derived macrolide named mycolactone was shown to reproduce many of the histopathological hallmarks of BU disease, inducing extensive tissue necrosis and microvascular thrombosis, in a dose-dependent way [12, 13]. Specifically, mycolactone provokes apoptotic cell death by driving expression of pro-apoptotic proteins BCL2L11 (Bim) and Fas and inhibiting cell cycle progression [14-16]. Furthermore, this toxin has the remarkable ability to bind to the alpha subunit of the Sec61 translocon in the endoplasmatic reticulum (ER), impeding posttranslational modifications, such as glycosylation, and translocation of newly synthesized membrane and secretory proteins into and across the ER membrane [17, 18]. Eventually, cytokines interferon gamma (IFN- $\gamma$ ), tumor necrosis factor alpha (TNF- $\alpha$ ), interleukin (IL) 6 and cyclooxygenase (Cox) 2, as well as a variety of other secreted proteins, end up in the cytosol, being marked for proteasome degradation $[17,18]$. Lastly, mycolactone also disturbs several pathways related to stress response, collagen biosynthesis and cytoskeleton dynamics, the latter mainly achieved by hyperactivation of the Wiskott-Aldrich syndrome protein (WASP) [19, 20].

The pleiotropic effects of mycolactone make $M$. ulcerans infection a unique paradigm of successful manipulation of the host immune orchestra. By inducing cellular death and preventing the generation and processing of crucial signaling molecules, the ability of the host to cope with the pathogen becomes severely crippled. Thus, what the actual role of the immune system is in BU, is a question of utmost importance to understand the disease.

\section{Host Attempts to Control Mycobacterium ulcerans Infection}

\subsection{Local Immune Response}

Due to its indolent course and various clinical presentations, characterizing the kinetics of the immune response against $M$. ulcerans in humans has always been a challenge. It is therefore not surprising that much of what is known about BU pathogenesis today came from studies resorting to animal models, which seem to present several resemblances to the human findings [1, 21-23].

Although understanding the very early stages of the contact of M. ulcerans with the host is still of extreme difficulty, it is currently thought that the pathogen depends on skin surface injuries or transmission vectors to penetrate the epidermal layer of the skin, highly rich in keratinocytes [24-26]. The importance of these cells for BU pathogenesis became evident when it was discovered that upon recognition of $M$. ulcerans through dectin-1, toll-like receptor (TLR) 2 and to a lesser extent TLR4, keratinocytes produced bactericidal reactive oxygen species and cathelicidin, as well as chemokines IL-8 and the monocyte chemoattractant protein (MCP) 1 [27]. 
Once mycolactone-producing strains of $M$. ulcerans reach the subcutaneous tissue, there is an influx, within the first hours, of neutrophils to the center of the lesion and of major histocompatibility complex (MHC) class $\mathrm{II}^{+}$cells to the periphery of the infection foci, followed by a sustained recruitment of macrophages for at least a week $[22,28]$. During this stage, mycobacteria are phagocytosed and, with the contribution of the activity of its superoxide dismustase and catalase enzymes, transiently replicate within phagosomes [9, 29]. Upon replication, the pathogen is released to the extracellular space, accumulating in the newly formed necrotic areas where it perpetuates the cycle of mycolactone production, leading to the generation of acellular foci that continuously expand $[9,22]$. Mycolactone further exacerbates this process by unbalancing the levels and activation state of thrombomodulin, protein $\mathrm{C}$ and other factors belonging to the coagulation cascade, favoring fibrin deposition and subsequent vessel thrombosis [30, 31]. As a consequence, the central necrotic area shows a high number of extracellular bacilli, surrounded by an infiltrate of neutrophils, macrophages and lymphocytes located in the interface between the necrotic area and healthy tissue [22]. With the inability of the immune system to reach the mycolactone producing-mycobacteria, the infection then progresses with the appearance of edema and ulceration of the epidermis, which can be potentiated by the coalescence of several foci of infection, if present [22].

Production of different congeners of mycolactone by different $M$. ulcerans lineages may alter the aggressiveness of the disease or even lead to distinct phenotypes, as it was initially observed in humans and later confirmed in mice [22, 23, 32-34]. In fact, in a proteomics study comparing a wild type (WT) mycolactoneproducing strain with a mycolactone-negative strain isolated from a transposon library, several proteins related to virulence and stress response factors were found to be upregulated in the mycolactone-negative strain [35]. In practice, in the absence of mycolactone, as in the case of the natural mutant Mexican isolate 5114, infection with M. ulcerans resembles other mycobacterial infections [22, 23, 36]. Indeed, after an initial influx of neutrophils, well-formed granuloma-like structures, mostly composed of macrophages with epithelioid transformation and of lymphocytes, organize in the following days to weeks and surround the proliferating mycobacteria $[12,22,23]$. These inflammatory infiltrates eventually distribute homogeneously in the subcutaneous and muscle tissue, with no apparent necrosis or alterations occurring in the epidermal layer of the skin [12, 22, 23]. Surprisingly, the fact that mice are seemingly unable to eliminate the mycolactone-negative mutants for at least 12 months suggests that the bacteria use additional mycolactone-independent mechanisms to evade the immune system [22]. It should be noted that many of the classical mycobacterial virulence factors, such as the $6 \mathrm{kDa}$ early secretory antigenic target (ESAT-6), the $10 \mathrm{kDa}$ culture filtrate antigen (CFP-10) or alphacrystallin-like protein $(\mathrm{HspX})$ present in the Mexican ancestral lineage strain, are also highly immunogenic, thus indicating that this $M$. ulcerans lineage has evolved to survive regardless of their presence $[37,38]$.

These studies are unveiling how mycolactone shapes the cellular landscape of BU, but dose-response analyses reveal in more detail the high degree of pleiotropism presented by this toxin. Right from the inception of the immune response, 
mycolactone is able to affect the phagocytic capacity of murine macrophages at high multiplicities of infection and to inhibit the production of a series of human and murine monocytic/macrophagic molecules, including the proinflammatory cytokine TNF- $\alpha$ [9, 12, 15, 28, 39, 40]. Moreover, it hinders the production of nitrous oxide species, assumed to be important to control the infection, according to in vitro experiments and a clinical trial with BU patients [41-43].

Mycolactone also possesses dose-dependent immunomodulatory effects on $\mathrm{T}$ cells and dendritic cells (DC). Besides suppressing DCs' maturation, migration and production of the chemokines macrophage inflammatory protein (MIP) $1 \alpha$ and MIP-1 $\beta$, regulated on activation normal T cell expressed and secreted (RANTES), IFN- $\gamma$-inducible protein $10 \mathrm{kD}$ and MCP-1, Sec61 blockade in DCs results in the suppression of direct and cross-presentation of synthetic peptides to $\mathrm{CD} 8^{+} \mathrm{T}$ cells by downregulation of MHC class I and $\beta 2$ microglobulin [44, 45]. As for T cells, mycolactone represses TNF- $\alpha$ activity over factor nuclear kappa B (NF- $\mathrm{B})$ and transcription and post translation of the $\mathrm{T}$ cell receptor, ultimately resulting in the blockage of IL-2 production, an essential cytokine for T cell proliferation $[15,46]$.

Although all of these mechanisms hinder cell-mediated immunity (CMI), none has been as extensively tested in in vivo models as IFN- $\gamma$, the hallmark cytokine of type $1 \mathrm{~T}$ helper $\left(\mathrm{T}_{\mathrm{H}} 1\right)$ responses. Indeed, mice infected with $M$. ulcerans strains of low and intermediate virulence produce increased levels of IFN- $\gamma$, which induce phagosome maturation and acidification, as well as nitrite production [43]. Likewise, IFN- $\gamma^{-1-}$ mice display a severe impairment in the growth control of lower virulence strains when compared with WT mice [43, 47]. Importantly, none of these phenomena are observed upon inoculation with highly virulent strains or high doses of mycolactone, which demonstrates the extent to which mycolactone can damage an otherwise protective immune response [43, 47].

Responses against $M$. ulcerans infection are therefore dependent on the amount/ variant of mycolactone produced by the pathogen. While many authors recognize the importance of CMI, the accumulation of mycolactone disturbing a wide array of CMI processes and the occupation by the mycobacteria of the extracellular space for most of the infection period places several question marks on what is or would be the ideal protective immune response. As such, other degrees of evidence are needed to develop a more accurate picture.

\subsection{Regional and Systemic Responses}

Viable M. ulcerans bacilli can be seen in the draining lymph node (DLN) of mice very early after subcutaneous infection, where cells initiate an immune response, as measured by their production of IFN- $\gamma$ upon ex-vivo stimulation [28]. However histological analyses of the DLN also reveal the typical pattern of cell depletion and/or necrosis, affecting in this case both the T and the B cell compartments [48]. Remarkably, albeit $\mathrm{T}$ cells show an impairment in their proliferative capacity to expand upon antigenic stimuli, they are deemed to be relatively resistant to cell death by mycolactone $[46,49]$. In contrast, mycolactone interferes with murine $\mathrm{T}$ 
cell expression of L-selectin (CD62-L), a necessary molecule to home these cells to the peripheral lymph nodes [49]. Whilst these findings in animal models of infection were so far not validated in humans, the indication that mycolactone can target cell homing mechanisms warrants further investigation [31, 49].

Both in humans and mice, M. ulcerans is occasionally found in internal organs, but probably due to its restrictive growth temperature, its viability there decreases over time and infection does not effectively establish [50-54]. Relevantly, mycolactone also disseminates systemically and, in spite of not causing major cell death or compromising immunity against other intracellular pathogens, it does alter the cytokine production of circulating cells $[52,54,55]$. As a result, some authors scrutinized the cytokine production pattern of peripheral blood cells from BU-infected patients, which did not lead to consistent results. Understandably, this can be attributed to differences in the genetic background of the study populations, the virulence of endemic $M$. ulcerans strains, the cells or stimuli applied in the assays used or even the power of the studies. IFN- $\gamma$, the most thoroughly analyzed cytokine until now, is the paradigm of this aspect, with some studies reporting opposite outcomes [56-63]. Nonetheless, the most consensual view until now is that $\mathrm{BU}$ is associated with an impaired $\mathrm{T}_{\mathrm{H}} 1$ response, resulting in a lower proliferation of peripheral blood mononuclear cells (PBMCs) and production of IFN- $\gamma$ upon stimulation [57, 60, 63, 64]. A deeper analysis of published studies further reveals that altough this response is not correlated with the stage of the lesion, it systematically returns in patients with healed lesions to the profile found in controls from endemic regions [59, 63]. Moreover, reports indicate that there is a correlation between the histological characteristics of a lesion and cytokine production, as patients who present well-formed granulomas stain more positively for IFN- $\gamma$, whereas patients without these structures tended to have more IL-10+ cells $[61,65]$. Interestingly, ex vivo IL-10 production by circulating leukocytes was found to increase during active disease in many of the studies, even if this was not statistically significant in some of them [56, 58-60, 62].

Consistent with some data in rodents, it was found that the production of chemokines such as IL-8, MIP-1 $\beta$ and MCP-1 was suppressed in BU patients throughout the different stages of the disease, strongly supporting the notion that $M$. ulcerans infection leads to a defect in immune cell recruitment in advanced stages of the infectious process [27, 44, 59]. A more recent analysis in humans with active BU confirmed the downregulation of MIP- $1 \beta$ and MCP-1 in the serum of patients, opening up a possibility to use certain chemokines as a molecular signature of the disease [31].

More extensive multi-analyte profiling of serum proteins in BU patients and endemic controls revealed that, although the disease does not influence significantly the leukocyte composition of the peripheral blood, it impacts an even wider array of circulating molecules $[31,66]$. Indeed, several of these analytes contribute to acute phase reaction, metabolism, coagulation and tissue remodeling, with some of them already having been implicated in healing speed [31, 66]. Specifically regarding metabolic factors, $M$. ulcerans not only interferes with energy-generation, but also with peptide, lipid and nucleotide pathways [66]. Even though many of these alterations seem to be in line with the expected response of the host to infectious 
processes, others, as the proposed impairment of the tricarboxylic acid (TCA) cycle, could be the result of a direct effect of mycolactone $[66,67]$. In reality, among TCA cycle intermediates, patients with BU have decreased citrate levels, whose relevance in other infectious diseases is associated with generating prostaglandins, nitric oxide and other antimicrobial peptides [66, 67].

All of these studies provide indications that the repercussions of $M$. ulcerans are more widespread than initially thought. While the disease focus is in the subcutaneous tissue, the ability of mycolactone to exert its actions beyond this local site most certainly contributes to the establishment of a permissive environment for the growth of the pathogen. This further hints on many other aspects of infection, such as immune cell metabolism, which are likely determinants for the way host cells interact with the pathogen.

\section{Diagnostics Research Make it Evident: The Triggering of Cellular and Humoral Arms}

Early attempts to find a better BU diagnostic method culminated in the development of burulin, a whole cell lysate of M. ulcerans that induced a delayed-type hypersensitive response in individuals from BU-endemic regions, more noticeable in people with already healed lesions [68-70]. Unfortunately, patients presented an equally strong reaction to tuberculin, consequently making the test of little usefulness in regions where tuberculosis is also prevalent or where the majority of the population is vaccinated with Bacillus Calmette-Guérin (BCG) [69, 70]. Furthermore, PBMCs from BU patients were later shown to proliferate very little and produce only small amounts of IFN- $\gamma$ upon stimulation with live or dead $M$. ulcerans when compared to healthy individuals with a positive tuberculin test [64]. In contrast, a significant proportion of the evaluated patients possessed M. ulcerans-specific antibodies, which contrary to the cellular responses, can be detected in significant amounts throughout the different stages of the disease [64, 69]. Interestingly, incubation of serum from healthy endemic family controls with an M. ulcerans culture filtrate also revealed a notable amount of specific immunoglobulin (Ig) G, but no IgM, implying that this latter class of Igs has more potential for the identification of new BU cases [71]. In accordance, most epidemiological studies managed to screen populations in contact with $M$. ulcerans with moderate success, by focusing on detecting IgG against the $18 \mathrm{kDa}$ small heat shock protein (shsp), a constitutive M. ulcerans cell wall protein involved in biofilm production [72-75]. Screenings of M. ulcerans whole protein lysates also identified the $65 \mathrm{kDa}$ heat shock protein (Hsp65) as a potential candidate for a serological approach to determine active BU disease [73]. However, this protein has homologs in other mycobacterial species, thus prompting further analysis on the specificity of such antibodies [77].

All in all, in addition to reinforcing a role for CMI in BU, the search for novel diagnostic methods has put some visibility on the presence of antibodies in the 
context of M. ulcerans exposure and infection. Regarding each of these aspects, it remains to be established why not all exposed individuals develop the disease and how antibodies contribute to the control of M. ulcerans infections.

\section{$4 \quad$ Antibiotic Treatment in the Aid of the Host Immune Response}

Antibiotic regimens based on the conjoint use of rifampicin with another drug have been used with success in the treatment of BU, rapidly killing M. ulcerans and restoring a vast array of processes needed for tissue homeostasis [78, 79]. Probably the most critical achievement of these drugs is to break the chain of mycolactone production, which allows mycolactone to wane from the system [80]. Indeed, direct correlations between mycolactone concentration and the time needed to heal BU lesions were established, suggesting this is a crucial factor for the immune response to re-establish [80]. Following this idea, both in humans and experimentally infected mice, treatment is associated with restoration of systemic levels of several inflammatory molecules, including IL-4, IL-7, granulocyte-macrophage colony-stimulating factor (GM-CSF), as well as the chemokines IL-8 and MCP-1 [59, 81]. Simultaneously, in contrast to the typical absence of local inflammatory infiltrates seen in the central area of active untreated BU lesions, patients undergoing chemotherapy display very diverse organizations of cellular immune infiltrates, including classical granulomas, diffuse infiltrates or dense lymphocyte aggregations [79, 82, 83]. While this likely corresponds to different stages of the healing process, it is not clear if these might also represent inter-individual differences among BU patients [79, 83, 84]. Nevertheless, it is perceivable amidst the different histological observations in both humans and experimentally infected mice under treatment that phagocytes are needed throughout the process for uptaking bacteria and cellular debris, paving the way for wound healing [79, 83-85]. In mice, the regional preservation of DLN structures is noticeable, including germinal centers, a pattern not common to untreated groups, possibly due to the persistence of viable mycolactoneproducing bacteria in the organ [85].

The immune break caused by mycolactone, in several reports described as paradoxical reactions in BU patients, has frequently been mistaken for treatment failure [86-89]. In fact, patients under standard regimens of antibiotherapy may display temporary clinical deterioration with local signs of increasing inflammation, ulceration and even development of new lesions [86, 87, 90]. These reactions appear to be due to the presence of large amounts of antigens, that once mycolactone starts to wane from the system, elicit a potent inflammatory response [86, 87]. In accordance, many of these paradoxical reactions appear to be related with age, duration of treatment, rapidly progressing forms of the disease such as edema, or even incomplete surgical lesion excisions that leave mycobacteria in surrounding tissues [86-88, 91, 92]. However, attempts to find biomarkers that could help to predict 
paradoxical reactions, such as neopterin, a catabolic product released by macrophages upon IFN- $\gamma$ stimulation, have so far failed [93]. While this makes it undeniably more difficult to prevent such phenomena, patients' symptoms have been successfully managed with corticosteroid adjunctive therapy [94, 95]. In a similar way, BU patients co-infected with human immunodeficiency virus (HIV) have benefited from such an approach, since they develop a comparable immune reconstitution syndrome once treatment with antiretroviral therapy starts [96, 97]. Although evidence is still relatively limited, HIV infected patients tend to generally develop BU more frequently and with worse clinical outcomes when compared to the general population, in spite of no direct correlation with the degree of immunosuppression having been established [96, 98-100]. On the other hand, immunomodulation with corticosteroids has been suggested to favor activation of latent $M$. ulcerans infection [101]. Moreover, these immunosuppressive drugs prolonged the time needed to completely resolve infection during antibiotherapy in mice, an effect attributed primarily to the disturbance of immune cell recruitment to the site of infection [101, 102].

As a whole, this reinforces the notion that $\mathrm{CMI}$ is critical for the control of BU. In this line, innate effector cells emerge as one of the most, if not the main responsible determinant for containing bacterial proliferation at the site of lesion. Still, to what degree their interaction with mycolactone-compromised $\mathrm{T}$ and B cells influences their activity and consequently the outcome of BU treatment is yet to be clarified.

\section{$5 \quad$ Epidemiological Clues and the Search for Novel Resistance and Susceptibility Markers}

More than ever, there has been an effort in integrating epidemiological and pathophysiological observations in a more comprehensive understanding of diseases [103]. The demography of BU has been however a source of debate, as efforts to identify risk populations have not always been conclusive [104]. Interestingly though, large observational studies appear to converge in some aspects: children under 15 years and the elderly are at a higher risk of contracting the disease, with the latter group also presenting more frequently severe phenotypes [92, 105-111]; and gender distribution of cases varies according to age group, with males tending to predominate in the younger ages and females in the adulthood $[105,107,108$, 110-113]. While these differences could be a product of behavioral exposure, they could too indicate an underlying physiological basis, which would be in agreement with the ascertained roles of age and sex in numerous infectious diseases, including other mycobacterioses [114, 115].

The incidence of tuberculosis in humans is also higher in children and older adults, albeit the clinical features tend to be distinct, probably as a consequence of the likewise distinct underlying immune response [116]. Nevertheless, in both these populations, Mycobacterium tuberculosis growth and active disease is predicted to be favored by an unbalance in the percentage of IFN- $\gamma^{+} \mathrm{CD} 4^{+} \mathrm{T}$ lymphocytes recruited to the infection site [117-120]. These findings were further replicated in 
aged murine models of tuberculosis infection and ultimately match the postulated importance of IFN- $\gamma$ in BU, which if not totally ablated by mycolactone, confers some degree of protection against $M$. ulcerans $[43,47,115,121]$. Therefore, taken all of this into account, stratification by age of the cellular and molecular profile of BU patients could provide a critical avenue to obtain new information on the determinants of susceptibility $v s$ protective immune responses, both collectively as well as in different age groups.

Parallel to age, the influence of sex over biological processes such as the immune response can be observed in a broad range of conditions, from infectious diseases to vaccination [122]. Even though some differences in the immune system of both genders are already established at birth, the effects become much more pronounced after puberty $[122,123]$. This suggests that differences in exposure to environmental reservoirs of $M$. ulcerans explain better the higher incidence of BU among male pre-pubertal children than sex-related biological differences. After puberty however, sex hormones start to exert a powerful influence over several pathways of both the innate and acquired immune system arms resulting, for instance, in a bias towards $T_{H} 2$ cells in females and $T_{H} 1$ cells in males [122]. Strikingly, both male humans and mice appear to be more vulnerable to mycobacterial infections than their female counterparts, an observation that has been attributed to the effects of testosterone on, among others, macrophage motility [124, 125]. However, considering that BU pathogenesis and clinical features are mainly attributed to the activities of mycolactone, any effect of sex hormones in the immune response should pass unnoticeable unless it is in relationship with the mechanism of action of the toxin. In this line, estrogen has been shown to be able to activate neural WASP through a phosphorylation cascade induced by focal adhesion kinase, which could then render the cells more prone to the actions of mycolactone $[20,126]$. In the end, this might be just one of several explanations for the seemingly increased susceptibility of adult women to the disease than men $[127,128]$.

Another debatable topic in $\mathrm{BU}$ is disease transmission. Although not the main focus of this chapter, some epidemiological records and experimental laboratory results point to environmental exposure as the main source for BU acquisition, namely through contact of injured skin with water bodies and through insect bites [25, 26, 113, 129-133]. However, some work in Africa, Asia and Australia additionally raised the possibility of host genetics playing a major part in BU development [92, 134-137]. Even though no evidence apart from anecdotal reports supports human-to-human transmission, the odds ratio (OR) of acquiring BU was determined as five times higher in people with family history of BU [25, 137-139]. Curiously, when this relationship was explored more thoroughly, strong associations with grandparent BU history but not contemporaneous family members were found [137]. In parallel, BU WHO category III lesions were recently suggested to constitute distinct clinical entities from categories I and II. When compared to both milder categories, they showed no dependency on time to develop and take considerably longer to heal $[89,109,140]$. Altogether, this strongly implies that additional host-intrinsic factors influence BU outcome, a lead followed by some studies 
evaluating the role of single nucleotide polymorphisms (SNPs) in genes related to the immune function (Table 1). For instance, confirmation of the critical importance of nitric oxide (NO) and IFN- $\gamma$ to BU pathogenesis was achieved, as SNPs leading to lower promoter activity of $i N O S$ and IFNG were associated with higher susceptibility to the disease [141].

However, genetic analyses are also helping to unravel the key function of other undisclosed molecular players of the immune system. Actually, the first ever human gene to be associated with BU was the solute carrier family 11 , member 1 (SLC11A1 or NRAMP1), whose main function is to transport divalent cations, including $\mathrm{Zn}^{2+}, \mathrm{Fe}^{2+}$ and $\mathrm{Mn}^{2+}$, to the late endosomal/lysosomal compartment [142, 143]. Since lysosomes eventually fuse with the phagosomes, where M. ulcerans resides transiently, this provides an important clue for the importance of the intramacrophage phase for the containment of $M$. ulcerans infection [9, 44, 143]. Accordingly, in a Beninese cohort of 208 patients, SNPs in autophagy-related genes E3 ubiquitin-protein ligase $(P A R K 2)$ and autophagy-related protein 16-1 (ATG16L1) were associated with susceptibility to disease acquisition and phenotype aggressiveness [144]. In the same line, two different polymorphisms in the gene encoding the nucleotide-binding oligomerization domain-containing 2 (NOD2) protein, which is involved in bacterial recognition, were also associated with disease phenotype [144]. In fact, in other infections with intracellular pathogens including some species of mycobacteria, NOD2, PARK2 and the autophagy process have been described to help to control bacterial load and to improve host survival $[145,146]$. Overall, this underlines a prominent role for xenophagy, the recognition and targeting of bacteria to autophagosomes, in the control of M. ulcerans infection, hence requiring further research (Table 1).

Table 1 Summary of genes significantly associated with BU disease susceptibility and or phenotype severity

\begin{tabular}{|c|c|c|c|c|c|c|}
\hline $\begin{array}{l}\text { First } \\
\text { author } \\
\text { and year }\end{array}$ & $\begin{array}{l}\text { Country } \\
\text { (Continent) }\end{array}$ & $\begin{array}{l}\text { Population } \\
\text { (n cases) }\end{array}$ & Gene & $\begin{array}{l}\text { SNP rs\# } \\
\text { number }\end{array}$ & Association & $\begin{array}{l}\text { Reported } \\
\text { adjusted } \\
\text { OR }(95 \% \\
\text { CI) }\end{array}$ \\
\hline $\begin{array}{l}\text { Stienstra } \\
\text { et al. } \\
\text { (2006) }\end{array}$ & $\begin{array}{l}\text { Ghana } \\
\text { (Africa) }\end{array}$ & 182 & $\begin{array}{l}\text { SLC11A1 } \\
\text { (NRAMP1) }\end{array}$ & rs 17235409 & $\begin{array}{l}\text { Disease } \\
\text { susceptibility }\end{array}$ & $\begin{array}{l}2.89 \\
(1.41-5.91)\end{array}$ \\
\hline \multirow{4}{*}{$\begin{array}{l}\text { Capela } \\
\text { et al. } \\
(2016)\end{array}$} & \multirow[t]{4}{*}{$\begin{array}{l}\text { Benin } \\
\text { (Africa) }\end{array}$} & \multirow[t]{4}{*}{208} & PARK2 & rs 1333955 & $\begin{array}{l}\text { Disease } \\
\text { susceptibility }\end{array}$ & $\begin{array}{l}1.43 \\
(1.00-2.06)\end{array}$ \\
\hline & & & \multirow[t]{2}{*}{ NOD2 } & rs9302752 & $\begin{array}{l}\text { WHO lesion } \\
\text { category }\end{array}$ & $\begin{array}{l}2.23 \\
(1.14-4.37)\end{array}$ \\
\hline & & & & rs2066842 & $\begin{array}{l}\text { WHO lesion } \\
\text { category }\end{array}$ & $\begin{array}{l}12.7 \\
(0.60-269)\end{array}$ \\
\hline & & & ATG16L1 & rs2241880 & $\begin{array}{l}\text { Lesion } \\
\text { ulceration }\end{array}$ & $\begin{array}{l}0.35 \\
(0.13-0.90)\end{array}$ \\
\hline \multirow{2}{*}{$\begin{array}{l}\text { Bibert } \\
\text { et al. } \\
(2017)\end{array}$} & \multirow[t]{2}{*}{$\begin{array}{l}\text { Ghana } \\
\text { (Africa) }\end{array}$} & \multirow[t]{2}{*}{96} & $i N O S$ & rs9282799 & $\begin{array}{l}\text { Disease } \\
\text { susceptibility }\end{array}$ & $\begin{array}{l}1.99 \\
(1.22-3.26)\end{array}$ \\
\hline & & & $I F N G$ & rs2069705 & $\begin{array}{l}\text { Disease } \\
\text { susceptibility }\end{array}$ & $\begin{array}{l}1.56 \\
(1.14-1.99)\end{array}$ \\
\hline
\end{tabular}


Given the contribution of many genes to a clinical phenotype, gene association analyses can also present some interpretation challenges: single studies often lack the necessary power to control for all interactions, and genetic polymorphisms can not only vary in frequency, but additionally have different functional consequences among different populations [147]. A good example is the lack of association of PARK2 with susceptibility to BU, as recently described in Ghana [141]. Although seemingly conflicting with previous results, the study populations were different and the tested polymorphisms were not the same, thus making direct data comparison difficult. Taken as a whole nonetheless, these population studies hold potential for a better understanding of host immune responses against BU, due to their ability to suggest, identify, or confirm potentially relevant targets for patient stratification or even disease treatment that could provide indispensable for future public health interventions.

\section{6 (Un)successful Preventive Approaches}

As of now, the only available vaccine targeting mycobacterial diseases is the BCG vaccine, a live attenuated bovine tuberculosis bacillus (Mycobacterium bovis) widely deployed against tuberculosis, but under an intense scrutiny for its unsatisfactory results [148]. In the case of BU, even though BCG appears to decrease the incidence of osteomyelitis forms, the incidence of new BU cases remains mostly unaltered, reinforcing the urge for better alternatives [149-155].

Efforts to develop a specific vaccine against $M$. ulcerans started several decades ago. Initial immunization studies in mice with different live mycobacterial species, including BCG and $M$. ulcerans, looked very promising in preventing the development of footpad swelling upon later challenge with M. ulcerans [156]. However, more recent experimental data clarified that even if a booster dose of the vaccine is administered or if the dose of $M$. ulcerans challenge is lowered, mice are only able to contain the infection for a short period of time, which is in accordance with observations in humans $[48,157,158]$. Nevertheless, these data provide important hints on the determinants of a protective immune response, some of which in agreement with what is seen during M. ulcerans clearance upon antibiotic treatment. Indeed, BCG-immunized mice display visible local cellular infiltrates together with a more rapid and sustained increase of IFN- $\gamma$ and TNF- $\alpha$ levels and, in later time points, of the chemotactic MIP-2 and of inducible nitric oxide synthase (iNOS) ${ }^{+}$cells [48]. Concomitantly, a prolonged presence of $\mathrm{CD}^{+} \mathrm{T}$ cells producing IFN- $\gamma$ is evident in murine DLN, indicating that the trafficking of the bacteria to the DLN and subsequent presentation to the T cell compartment is temporarily being achieved [48]. Interestingly, immunization with a mycolactone-negative M. ulcerans strain appeared to be less effective than BCG in attracting cells to the site of the lesion and in inducing iNOS $^{+}$cell accumulation [48]. On the other hand, in a study employing dewaxed $M$. ulcerans one month before infection, a strong generation of $\mathrm{IgG}$ against the bacilli was observed, with very little bacilli present in footpad 
sections and no phenotype development [159]. However, this study only evaluated protection for 28 days, and thus it remains to be investigated whether protection is long-lasting. Moreover, it is unclear if protective immunogens could have been removed during the dewaxing process, in spite of a general lack of protection detected in immunization interventions employing surface proteins, such as the $18 \mathrm{kDa}$ shsp and the $27 \mathrm{kDa}$ laminar binding protein $[32,160,161]$. Still, these results add to others confirming the extreme hydrophobicity of the M. ulcerans cell wall, which cumulatively with mycolactone represents a virulence factor and aids in shielding the pathogen from immune surveillance mechanisms, consequently adding another layer of complexity to the development of preventive strategies [162].

Other immunization alternatives have thus been tested, such as vaccination with the mycolyl-transferase antigen 85A (Ag85A), a major secreted member of a family of proteins with important cell wall synthetic activity in several mycobacterial species, including $M$. ulcerans $[163,164]$. Whether in the form of a plasmid DNA vaccine or as a recombinant protein, vaccination strategies with Ag85A conferred some degree of protection by eliciting a cellular response with high levels of IFN- $\gamma$, IL-2 and Ag85-specific IgGs, but, similarly to BCG, eventually failed to deter disease development [163-166]. Likewise, a vaccine employing DNA plasmids of polyketide synthase domains of Mycobacterium leprae Hsp65, previously tested in a murine model of tuberculosis, conferred protection against BU only for a few months, despite the high homology of the amino acid sequence with the M. ulcerans orthologue $[167,168]$. Therefore, better targets for immunization are still to be found and, to this end, a comparative genomics screening study identified several essential components of $M$. ulcerans that could provide important hints to direct future vaccination strategies [169].

So, why did not any of these immunization attempts succeed? Even if a transient protective response against $M$. ulcerans is generated, bacteria are consistently able to overcome it at some point. This likely implies that, unless elimination of the replication of the bacilli is achieved at the very early stages post-infection, accumulation of mycolactone will eventually begin to significantly damage the surrounding tissue including immune cells, thus defending the pathogen and downplaying any protective immune mechanism. Indeed, the administration of either antibiotics or bacteriophages in M. ulcerans infected mice corroborate this interpretation, since the killing of M. ulcerans is accompanied by an increase in the cellular immune response associated with cytokines such as IFN- $\gamma[85,170,171]$.

In this sense, neutralization of mycolactone itself seems to be an appealing target both for passive or active immunization strategies, as it would open the necessary opportunity for the immune response against $M$. ulcerans to develop and maintain effectively. This is not a novel concept, but has been for long hampered by the lipidlike nature of mycolactone, which makes it poorly immunogenic [168, 172]. However, recently, anti-mycolactone IgG antibodies were generated in mice through the administration of a protein conjugate of a truncated non-cytotoxic form of the toxin [173]. Although these antibodies were able to bind to mycolactone and to 
neutralize its effect in in vitro assays with L929 fibroblast cell lines, it remains to be clarified if the antibodies are protective in vivo and if immunization with the truncated form of mycolactone induces a long-lasting protective humoral response [173]. Nevertheless, these are promising steps for future strategies targeting both active immunization efforts of endemic populations and passive immunization of BU patients.

\section{$7 \quad$ Novel Models for Investigation and Future Perspectives}

Research on BU includes a wide range of animal models, ranging from mammals and reptiles to birds, in an attempt to find one mimicking human disease best and allowing a detailed study of the pertaining cellular and molecular events $[3,174$ 177]. Nonetheless, most of the evidence on BU pathophysiology and the host immune response has originated from experimentally infected mice, which, in spite of mimicking most of the clinical features of human BU, such as erythema, edema and ulcers, tend to progress very rapidly to necrosis [50]. In an attempt to directly tackle this issue, in vitro sub-culturing of a M. ulcerans Ghanaian isolate (NM20/02) resulted in an attenuated strain that allowed a more prolonged evaluation of the cellular infiltrates [32]. Additionally, the extended kinetics facilitated the confirmation of other studies disclosing murine strain-specificities in the response against $M$. ulcerans infection, with overall evidence indicating that $\mathrm{BALB} / \mathrm{c}$ mice are able to delay bacterial growth and respond more effectively to BCG immunization than their C57BL/6 counterparts [21, 32, 157]. This critical point to be considered when extrapolating data to the human pathophysiology, can eventually be overcome by the addition of information from other animal models with more similarities with the human skin, such as pigs and guinea pigs [174, 175, 178, 179].

Intriguingly, whereas many of the above models have been very useful to learn about the disease pathogenesis, very little progress was made concerning the mechanisms behind natural resistance to the disease. In fact, for long it has been known that natural resistance to $M$. ulcerans infection occurs in some animal species and some studies also indicated the potential for spontaneous healing of BU lesions in humans [3, 86, 176, 180-183]. On the other hand, it is estimated that even with proper antibiotic and surgical treatment, more than $20 \%$ of patients develop permanent sequelae [111]. What causes lie between these two extremes? Two recent studiesaimed to shed some light on this question, by exploring the ability of the Hartley guinea pigs and the FVB/N mice to spontaneously heal BU [21, 184]. Strikingly, whereas the guinea pigs were able to achieve sterilizing immunity, FVB/N mice appear to halt the production of mycolactone by $M$. ulcerans without being able to completely eliminate the pathogen [21, 184]. Considering for instance, that changes in the sugar content of the growth medium of $M$. ulcerans can affect its production of mycolactone and antigens, this raises the hypothesis whether FVB/ $\mathrm{N}$ mice deal with the infection by manipulating the local environment [185]. It is intriguing to observe that both models control the infection regardless of the initial inoculum, 
which most likely suggests that there are key host factors that can effectively hamper the progression of the infection and that have never been so far considered as preventive or therapeutic approaches [21, 184]. Hence, it is highly likely that answers to this conundrum lie within the genetic makeup of BU patients that spontaneously recover from the disease, but with the current widespread use of antibiotics, the task of identifying such cases is extremely difficult. Nevertheless, the existence of animal models of resistance already constitutes an exciting opportunity that should be seized to unravel what factors could be exploited in order to overturn a progressive disease into a state of full resolution.

\section{Conclusions}

For a long time, research on $M$. ulcerans infection has been highly focused on experimental models. While these led to many important advances, integration of recent progress in epidemiological, clinical, cellular and molecular research constitutes an opportunity to further our understanding of BU pathogenesis. In this context, several lines of evidence point towards the importance of CMI in the local interaction with invading $M$. ulcerans bacilli, but the scope of this contact is still widely unknown. Likewise, bearing in mind that mycolactone can act beyond the site of infection, the consequences of its influence on the systemic production of cytokines or metabolic networks of the immune cells are yet to be understood. As such, it would be important to determine how immune recognition of M. ulcerans occurs at the molecular level, what host factors influence cytokine production upon this recognition and what the effect of this interaction is on CMI effector mechanisms. As for the humoral immunity, it would also be paramount to understand what its importance is and to what extent it prevents or delays the progression of the disease. It is only if answers for these fundamental questions are found, that the way to tailor more effective vaccination and prophylactic measures will become clear.

Acknowledgements This work was developed under the scope of the project NORTE-01-0145FEDER-000013, supported by the Northern Portugal Regional Operational Programme (NORTE 2020), under the Portugal 2020 Partnership Agreement, through the European Regional Development Fund (FEDER); FEDER, through the Competiveness Factors Operational Programme (COMPETE) and by National funds, through the Foundation for Science and Technology (FCT), under the scope of projects POCI-01-0145-FEDER-007038 and POCI-010145-FEDER-031312; Infect-ERA grant Infect-ERA/0002/2015; and FCT through the PhD grant $\mathrm{PD} / \mathrm{BD} / 113699 / 2015$ to JF and the postdoctoral grant SFRH/BPD/112903/2015 to AGF.

\section{References}

1. Dodge OG (1964) Mycobacterial skin ulcers in Uganda: histopathological and experimental aspects. J Pathol Bacteriol 88:169-174

2. Hayman J (1993) Out of Africa: observations on the histopathology of Mycobacterium ulcerans infection. J Clin Pathol 46:5-9 
3. MacCallum P, Tolhurst JC (1948) A new mycobacterial infection in man. J Pathol Bacteriol 60:93-122

4. Connor DH, Lunn HF (1965) Mycobacterium ulcerans infection (with comments on pathogenesis). Int J Lepr 33(Suppl):698-709

5. Guarner J, Bartlett J, Whitney EAS et al (2003) Histopathologic features of Mycobacterium ulcerans infection. Emerg Infect Dis 9:651-656

6. Hayman J, McQueen A (1985) The pathology of Mycobacterium ulcerans infection. Pathology (Phila) 17:594-600

7. Rondini S, Horsfield C, Mensah-Quainoo E et al (2006) Contiguous spread of Mycobacterium ulcerans in Buruli ulcer lesions analysed by histopathology and real-time PCR quantification of mycobacterial DNA. J Pathol 208:119-128. https://doi.org/10.1002/path.1864

8. Ruf M-T, Steffen C, Bolz M et al (2017) Infiltrating leukocytes surround early Buruli ulcer lesions, but are unable to reach the mycolactone producing mycobacteria. Virulence 8:19181926. https://doi.org/10.1080/21505594.2017.1370530

9. Torrado E, Fraga AG, Castro AG et al (2007) Evidence for an intramacrophage growth phase of Mycobacterium ulcerans. Infect Immun 75:977-987. https://doi.org/10.1128/ IAI.00889-06

10. Walsh DS, Meyers WM, Portaels F et al (2005) High rates of apoptosis in human Mycobacterium ulcerans culture-positive Buruli ulcer skin lesions. Am J Trop Med Hyg 73:410-415

11. Krieg RE, Hockmeyer WT, Connor DH (1974) Toxin of Mycobacterium ulcerans. Production and effects in Guinea pig skin. Arch Dermatol 110:783-788

12. Adusumilli S, Mve-Obiang A, Sparer T et al (2005) Mycobacterium ulcerans toxic macrolide, mycolactone modulates the host immune response and cellular location of $\mathrm{M}$. ulcerans in vitro and in vivo. Cell Microbiol 7:1295-1304. https://doi.org/10.1111/j.1462-5822.2005.00557.x

13. George KM, Chatterjee D, Gunawardana G et al (1999) Mycolactone: a polyketide toxin from Mycobacterium ulcerans required for virulence. Science 283:854-857

14. Bieri R, Scherr N, Ruf M-T et al (2017) The macrolide toxin mycolactone promotes bimdependent apoptosis in Buruli ulcer through inhibition of mTOR. ACS Chem Biol 12:12971307. https://doi.org/10.1021/acschembio.7b00053

15. Pahlevan AA, Wright DJ, Andrews C et al (1999) The inhibitory action of Mycobacterium ulcerans soluble factor on monocyte/T cell cytokine production and NF-kappa B function. J Immunol 163:3928-3935

16. Snyder DS, Small PLC (2003) Uptake and cellular actions of mycolactone, a virulence determinant for Mycobacterium ulcerans. Microb Pathog 34:91-101

17. Baron L, Paatero AO, Morel J-D et al (2016) Mycolactone subverts immunity by selectively blocking the Sec61 translocon. J Exp Med 213:2885-2896. https://doi.org/10.1084/ jem.20160662

18. Hall BS, Hill K, McKenna M et al (2014) The pathogenic mechanism of the Mycobacterium ulcerans virulence factor, mycolactone, depends on blockade of protein translocation into the ER. PLoS Pathog 10:e1004061. https://doi.org/10.1371/journal.ppat.1004061

19. Gama JB, Ohlmeier S, Martins TG et al (2014) Proteomic analysis of the action of the Mycobacterium ulcerans toxin mycolactone: targeting host cells cytoskeleton and collagen. PLoS Negl Trop Dis 8:e3066. https://doi.org/10.1371/journal.pntd.0003066

20. Guenin-Macé L, Veyron-Churlet R, Thoulouze M-I et al (2013) Mycolactone activation of Wiskott-Aldrich syndrome proteins underpins Buruli ulcer formation. J Clin Invest 123:1501-1512. https://doi.org/10.1172/JCI66576

21. Marion E, Jarry U, Cano C et al (2016) FVB/N mice spontaneously heal ulcerative lesions induced by Mycobacterium ulcerans and switch M. ulcerans into a low mycolactone producer. J Immunol 196:2690-2698. https://doi.org/10.4049/jimmunol.1502194

22. Oliveira MS, Fraga AG, Torrado E et al (2005) Infection with Mycobacterium ulcerans induces persistent inflammatory responses in mice. Infect Immun 73:6299-6310. https://doi. org/10.1128/IAI.73.10.6299-6310.2005 
23. Ortiz RH, Leon DA, Estevez HO et al (2009) Differences in virulence and immune response induced in a murine model by isolates of Mycobacterium ulcerans from different geographic areas. Clin Exp Immunol 157:271-281. https://doi.org/10.1111/j.1365-2249.2009.03941.x

24. Guenin-Macé L, Oldenburg R, Chrétien F, Demangel C (2014) Pathogenesis of skin ulcers: lessons from the Mycobacterium ulcerans and Leishmania spp. pathogens. Cell Mol Life Sci 71:2443-2450. https://doi.org/10.1007/s00018-014-1561-z

25. Merritt RW, Walker ED, Small PLC et al (2010) Ecology and transmission of Buruli ulcer disease: a systematic review. PLoS Negl Trop Dis 4:e911. https://doi.org/10.1371/journal. pntd.0000911

26. Wallace JR, Mangas KM, Porter JL et al (2017) Mycobacterium ulcerans low infectious dose and mechanical transmission support insect bites and puncturing injuries in the spread of Buruli ulcer. PLoS Negl Trop Dis 11:e0005553. https://doi.org/10.1371/journal.pntd.0005553

27. Lee H-M, Shin D-M, Choi D-K et al (2009) Innate immune responses to Mycobacterium ulcerans via toll-like receptors and dectin-1 in human keratinocytes. Cell Microbiol 11:678692. https://doi.org/10.1111/j.1462-5822.2009.01285.x

28. Coutanceau E, Marsollier L, Brosch R et al (2005) Modulation of the host immune response by a transient intracellular stage of Mycobacterium ulcerans: the contribution of endogenous mycolactone toxin. Cell Microbiol 7:1187-1196. https://doi. org/10.1111/j.1462-5822.2005.00546.x

29. Roberts B, Hirst R (1996) Identification and characterisation of a superoxide dismutase and catalase from Mycobacterium ulcerans. J Med Microbiol 45:383-387. https://doi. org/10.1099/00222615-45-5-383

30. Ogbechi J, Ruf M-T, Hall BS et al (2015) Mycolactone-dependent depletion of endothelial cell thrombomodulin is strongly associated with fibrin deposition in Buruli ulcer lesions. PLoS Pathog 11:e1005011. https://doi.org/10.1371/journal.ppat.1005011

31. Phillips RO, Sarfo FS, Landier J et al (2014) Combined inflammatory and metabolic defects reflected by reduced serum protein levels in patients with Buruli ulcer disease. PLoS Negl Trop Dis 8:e2786. https://doi.org/10.1371/journal.pntd.0002786

32. Bénard A, Sala C, Pluschke G (2016) Mycobacterium ulcerans mouse model refinement for pre-clinical profiling of vaccine candidates. PLoS One 11:e0167059. https://doi.org/10.1371/ journal.pone.0167059

33. Portaels F, Meyers WM, Ablordey A et al (2008) First cultivation and characterization of Mycobacterium ulcerans from the environment. PLoS Negl Trop Dis 2:e178. https://doi. org/10.1371/journal.pntd.0000178

34. Scherr N, Gersbach P, Dangy J-P et al (2013) Structure-activity relationship studies on the macrolide exotoxin mycolactone of Mycobacterium ulcerans. PLoS Negl Trop Dis 7:e2143. https://doi.org/10.1371/journal.pntd.0002143

35. Tafelmeyer P, Laurent C, Lenormand P et al (2008) Comprehensive proteome analysis of Mycobacterium ulcerans and quantitative comparison of mycolactone biosynthesis. Proteomics 8:3124-3138. https://doi.org/10.1002/pmic.200701018

36. Mve-Obiang A, Lee RE, Portaels F, Small PLC (2003) Heterogeneity of Mycolactones produced by clinical isolates of Mycobacterium ulcerans: implications for virulence. Infect Immun 71:774-783. https://doi.org/10.1128/IAI.71.2.774-783.2003

37. Huber CA, Ruf M-T, Pluschke G, Käser M (2008) Independent loss of immunogenic proteins in Mycobacterium ulcerans suggests immune evasion. Clin Vaccine Immunol 15:598-606. https://doi.org/10.1128/CVI.00472-07

38. Qi W, Käser M, Röltgen K et al (2009) Genomic diversity and evolution of Mycobacterium ulcerans revealed by next-generation sequencing. PLoS Pathog 5:e1000580. https://doi. org/10.1371/journal.ppat.1000580

39. Pimsler M, Sponsler TA, Meyers WM (1988) Immunosuppressive properties of the soluble toxin from Mycobacterium ulcerans. J Infect Dis 157:577-580

40. Sarfo FS, Phillips RO, Rangers B et al (2010) Detection of Mycolactone A/B in Mycobacterium ulcerans-infected human tissue. PLoS Negl Trop Dis 4:e577. https://doi.org/10.1371/journal. pntd.0000577 
41. Phillips R, Adjei O, Lucas S et al (2004) Pilot randomized double-blind trial of treatment of Mycobacterium ulcerans disease (Buruli ulcer) with topical nitrogen oxides. Antimicrob Agents Chemother 48:2866-2870. https://doi.org/10.1128/AAC.48.8.2866-2870.2004

42. Phillips R, Kuijper S, Benjamin N et al (2004) In vitro killing of Mycobacterium ulcerans by acidified nitrite. Antimicrob Agents Chemother 48:3130-3132. https://doi.org/10.1128/ AAC.48.8.3130-3132.2004

43. Torrado E, Fraga AG, Logarinho E et al (2010) IFN-gamma-dependent activation of macrophages during experimental infections by Mycobacterium ulcerans is impaired by the toxin mycolactone. J Immunol 184:947-955. https://doi.org/10.4049/jimmunol.0902717

44. Coutanceau E, Decalf J, Martino A et al (2007) Selective suppression of dendritic cell functions by Mycobacterium ulcerans toxin mycolactone. J Exp Med 204:1395-1403. https://doi. org/10.1084/jem.20070234

45. Grotzke JE, Kozik P, Morel J-D et al (2017) Sec61 blockade by mycolactone inhibits antigen cross-presentation independently of endosome-to-cytosol export. Proc Natl Acad Sci U S A 114:E5910-E5919. https://doi.org/10.1073/pnas.1705242114

46. Boulkroun S, Guenin-Macé L, Thoulouze M-I et al (2010) Mycolactone suppresses T cell responsiveness by altering both early signaling and posttranslational events. J Immunol 184:1436-1444. https://doi.org/10.4049/jimmunol.0902854

47. Bieri R, Bolz M, Ruf M-T, Pluschke G (2016) Interferon- $\gamma$ is a crucial activator of early host immune defense against Mycobacterium ulcerans infection in mice. PLoS Negl Trop Dis 10:e0004450. https://doi.org/10.1371/journal.pntd.0004450

48. Fraga AG, Martins TG, Torrado E et al (2012) Cellular immunity confers transient protection in experimental Buruli ulcer following BCG or mycolactone-negative Mycobacterium ulcerans vaccination. PLoS One 7:e33406. https://doi.org/10.1371/journal.pone.0033406

49. Guenin-Macé L, Carrette F, Asperti-Boursin F et al (2011) Mycolactone impairs T cell homing by suppressing microRNA control of L-selectin expression. Proc Natl Acad Sci U S A 108:12833-12838. https://doi.org/10.1073/pnas.1016496108

50. Addo P, Owusu E, Adu-Addai B et al (2005) Findings from a Buruli ulcer mouse model study. Ghana Med J 39:86-93

51. Fenner F (1956) The pathogenic behavior of Mycobacterium ulcerans and Mycobacterium balnei in the mouse and the developing chick embryo. Am Rev Tuberc 73:650-673

52. Hong H, Coutanceau E, Leclerc M et al (2008) Mycolactone diffuses from Mycobacterium ulcerans-infected tissues and targets mononuclear cells in peripheral blood and lymphoid organs. PLoS Negl Trop Dis 2:e325. https://doi.org/10.1371/journal.pntd.0000325

53. Pattyn SR (1965) Bactériologie et pathologie humaine et expérimentale des ulcères à Mycobacterium ulcerans. Ann Soc Belges Méd Trop Parasitol Mycol 45:121-129

54. Sarfo FS, Le Chevalier F, Aka N et al (2011) Mycolactone diffuses into the peripheral blood of Buruli ulcer patients-implications for diagnosis and disease monitoring. PLoS Negl Trop Dis 5:e1237. https://doi.org/10.1371/journal.pntd.0001237

55. Fraga AG, Cruz A, Martins TG et al (2011) Mycobacterium ulcerans triggers T-cell immunity followed by local and regional but not systemic immunosuppression. Infect Immun 79:421430. https://doi.org/10.1128/IAI.00820-10

56. Gooding TM, Johnson PDR, Smith M et al (2002) Cytokine profiles of patients infected with Mycobacterium ulcerans and unaffected household contacts. Infect Immun 70:5562-5567

57. Gooding TM, Kemp AS, Robins-Browne RM et al (2003) Acquired T-helper 1 lymphocyte anergy following infection with Mycobacterium ulcerans. Clin Infect Dis 36:1076-1077. https://doi.org/10.1086/368315

58. Phillips R, Horsfield C, Kuijper S et al (2006) Cytokine response to antigen stimulation of whole blood from patients with Mycobacterium ulcerans disease compared to that from patients with tuberculosis. Clin Vaccine Immunol 13:253-257. https://doi.org/10.1128/ CVI.13.2.253-257.2006

59. Phillips R, Sarfo FS, Guenin-Macé L et al (2009) Immunosuppressive signature of cutaneous Mycobacterium ulcerans infection in the peripheral blood of patients with Buruli ulcer disease. J Infect Dis 200:1675-1684. https://doi.org/10.1086/646615 
60. Prévot G, Bourreau E, Pascalis H et al (2004) Differential production of systemic and intralesional gamma interferon and interleukin-10 in nodular and ulcerative forms of Buruli disease. Infect Immun 72:958-965

61. Schipper HS, Rutgers B, Huitema MG et al (2007) Systemic and local interferon-gamma production following Mycobacterium ulcerans infection. Clin Exp Immunol 150:451-459. https://doi.org/10.1111/j.1365-2249.2007.03506.x

62. Westenbrink BD, Stienstra Y, Huitema MG et al (2005) Cytokine responses to stimulation of whole blood from patients with Buruli ulcer disease in Ghana. Clin Diagn Lab Immunol 12:125-129. https://doi.org/10.1128/CDLI.12.1.125-129.2005

63. Yeboah-Manu D, Peduzzi E, Mensah-Quainoo E et al (2006) Systemic suppression of interferon-gamma responses in Buruli ulcer patients resolves after surgical excision of the lesions caused by the extracellular pathogen Mycobacterium ulcerans. J Leukoc Biol 79:1150-1156. https://doi.org/10.1189/jlb.1005581

64. Gooding TM, Johnson PD, Campbell DE et al (2001) Immune response to infection with Mycobacterium ulcerans. Infect Immun 69:1704-1707. https://doi.org/10.1128/ IAI.69.3.1704-1707.2001

65. Kiszewski AE, Becerril E, Aguilar LD et al (2006) The local immune response in ulcerative lesions of Buruli disease. Clin Exp Immunol 143:445-451. https://doi. org/10.1111/j.1365-2249.2006.03020.x

66. Niang F, Sarfo FS, Frimpong M et al (2015) Metabolomic profiles delineate mycolactone signature in Buruli ulcer disease. Sci Rep 5:17693. https://doi.org/10.1038/srep17693

67. O'Neill LAJ, Kishton RJ, Rathmell J (2016) A guide to immunometabolism for immunologists. Nat Rev Immunol 16:553-565. https://doi.org/10.1038/nri.2016.70

68. Barker DJ (1973) Epidemiology of Mycobacterium ulcerans infection. Trans R Soc Trop Med Hyg 67:43-50

69. Dobos KM, Spotts EA, Marston BJ et al (2000) Serologic response to culture filtrate antigens of Mycobacterium ulcerans during Buruli ulcer disease. Emerg Infect Dis 6:158-164. https:// doi.org/10.3201/eid0602.000208

70. Stanford JL, Revill WD, Gunthorpe WJ, Grange JM (1975) The production and preliminary investigation of Burulin, a new skin test reagent for Mycobacterium ulcerans infection. J Hyg $74: 7-16$

71. Okenu DMN, Ofielu LO, Easley KA et al (2004) Immunoglobulin M antibody responses to Mycobacterium ulcerans allow discrimination between cases of active Buruli ulcer disease and matched family controls in areas where the disease is endemic. Clin Diagn Lab Immunol 11:387-391

72. Diaz D, Döbeli H, Yeboah-Manu D et al (2006) Use of the immunodominant 18-kiloDalton small heat shock protein as a serological marker for exposure to Mycobacterium ulcerans. Clin Vaccine Immunol 13:1314-1321. https://doi.org/10.1128/CVI.00254-06

73. Pidot SJ, Porter JL, Tobias NJ et al (2010) Regulation of the $18 \mathrm{kDa}$ heat shock protein in Mycobacterium ulcerans: an alpha-crystallin orthologue that promotes biofilm formation. Mol Microbiol 78:1216-1231. https://doi.org/10.1111/j.1365-2958.2010.07401.x

74. Röltgen K, Bratschi MW, Ross A et al (2014) Late onset of the serological response against the $18 \mathrm{kDa}$ small heat shock protein of Mycobacterium ulcerans in children. PLoS Negl Trop Dis 8:e2904. https://doi.org/10.1371/journal.pntd.0002904

75. Yeboah-Manu D, Röltgen K, Opare W et al (2012) Sero-epidemiology as a tool to screen populations for exposure to Mycobacterium ulcerans. PLoS Negl Trop Dis 6:e1460. https:// doi.org/10.1371/journal.pntd.0001460

76. Dreyer A, Röltgen K, Dangy JP et al (2015) Identification of the Mycobacterium ulcerans protein MUL_3720 as a promising target for the development of a diagnostic test for Buruli ulcer. PLoS Negl Trop Dis 9:e0003477. https://doi.org/10.1371/journal.pntd.0003477

77. Pidot SJ, Porter JL, Marsollier L et al (2010) Serological evaluation of Mycobacterium ulcerans antigens identified by comparative genomics. PLoS Negl Trop Dis 4:e872. https://doi. org/10.1371/journal.pntd.0000872 
78. Converse PJ, Nuermberger EL, Almeida DV, Grosset JH (2011) Treating Mycobacterium ulcerans disease (Buruli ulcer): from surgery to antibiotics, is the pill mightier than the knife? Future Microbiol 6:1185-1198. https://doi.org/10.2217/fmb.11.101

79. Ruf M-T, Schütte D, Chauffour A et al (2012) Chemotherapy-associated changes of histopathological features of Mycobacterium ulcerans lesions in a Buruli ulcer mouse model. Antimicrob Agents Chemother 56:687-696. https://doi.org/10.1128/AAC.05543-11

80. Sarfo FS, Phillips RO, Zhang J et al (2014) Kinetics of mycolactone in human subcutaneous tissue during antibiotic therapy for Mycobacterium ulcerans disease. BMC Infect Dis 14:202. https://doi.org/10.1186/1471-2334-14-202

81. Sarfo FS, Converse PJ, Almeida DV et al (2013) Microbiological, histological, immunologi$\mathrm{cal}$, and toxin response to antibiotic treatment in the mouse model of Mycobacterium ulcerans disease. PLoS Negl Trop Dis 7:e2101. https://doi.org/10.1371/journal.pntd.0002101

82. Ruf M-T, Sopoh GE, Brun LV et al (2011) Histopathological changes and clinical responses of Buruli ulcer plaque lesions during chemotherapy: a role for surgical removal of necrotic tissue? PLoS Negl Trop Dis 5:e1334. https://doi.org/10.1371/journal.pntd.0001334

83. Schütte D, Um-Boock A, Mensah-Quainoo E et al (2007) Development of highly organized lymphoid structures in Buruli ulcer lesions after treatment with rifampicin and streptomycin. PLoS Negl Trop Dis 1:e2. https://doi.org/10.1371/journal.pntd.0000002

84. Schütte D, Umboock A, Pluschke G (2009) Phagocytosis of Mycobacterium ulcerans in the course of rifampicin and streptomycin chemotherapy in Buruli ulcer lesions. Br J Dermatol 160:273-283. https://doi.org/10.1111/j.1365-2133.2008.08879.x

85. Martins TG, Gama JB, Fraga AG et al (2012) Local and regional re-establishment of cellular immunity during curative antibiotherapy of murine Mycobacterium ulcerans infection. PLoS One 7:e32740. https://doi.org/10.1371/journal.pone.0032740

86. Nienhuis WA, Stienstra Y, Abass KM et al (2012) Paradoxical responses after start of antimicrobial treatment in Mycobacterium ulcerans infection. Clin Infect Dis 54:519-526. https:// doi.org/10.1093/cid/cir856

87. O'Brien DP, Robson M, Friedman ND et al (2013) Incidence, clinical spectrum, diagnostic features, treatment and predictors of paradoxical reactions during antibiotic treatment of Mycobacterium ulcerans infections. BMC Infect Dis 13:416. https://doi.org/10.1186/1471-2334-13-416

88. O'Brien DP, Robson ME, Callan PP, McDonald AH (2009) "Paradoxical" immune-mediated reactions to Mycobacterium ulcerans during antibiotic treatment: a result of treatment success, not failure. Med J Aust 191:564-566

89. Sarfo FS, Phillips R, Asiedu K et al (2010) Clinical efficacy of combination of rifampin and streptomycin for treatment of Mycobacterium ulcerans disease. Antimicrob Agents Chemother 54:3678-3685. https://doi.org/10.1128/AAC.00299-10

90. Ruf M-T, Chauty A, Adeye A et al (2011) Secondary Buruli ulcer skin lesions emerging several months after completion of chemotherapy: paradoxical reaction or evidence for immune protection? PLoS Negl Trop Dis 5:e1252. https://doi.org/10.1371/journal.pntd.0001252

91. Barogui YT, Klis S-A, Johnson RC et al (2016) Genetic susceptibility and predictors of paradoxical reactions in Buruli ulcer. PLoS Negl Trop Dis 10:e0004594. https://doi.org/10.1371/ journal.pntd.0004594

92. O'Brien DP, Friedman ND, Cowan R et al (2015) Mycobacterium ulcerans in the elderly: more severe disease and suboptimal outcomes. PLoS Negl Trop Dis 9:e0004253. https://doi. org/10.1371/journal.pntd.0004253

93. de Zeeuw J, Duggirala S, Nienhuis WA et al (2013) Serum levels of neopterin during antimicrobial treatment for Mycobacterium ulcerans infection. Am J Trop Med Hyg 89:498-500. https://doi.org/10.4269/ajtmh.12-0599

94. Friedman ND, McDonald AH, Robson ME, O'Brien DP (2012) Corticosteroid use for paradoxical reactions during antibiotic treatment for Mycobacterium ulcerans. PLoS Negl Trop Dis 6:e1767. https://doi.org/10.1371/journal.pntd.0001767

95. Trevillyan JM, Johnson PDR (2013) Steroids control paradoxical worsening of Mycobacterium ulcerans infection following initiation of antibiotic therapy. Med J Aust 198:443-444 
96. Tuffour J, Owusu-Mireku E, Ruf M-T et al (2015) Challenges associated with management of Buruli ulcer/human immunodeficiency virus coinfection in a treatment center in Ghana: a case series study. Am J Trop Med Hyg 93:216-223. https://doi.org/10.4269/ajtmh.14-0571

97. Wanda F, Nkemenang P, Ehounou G et al (2014) Clinical features and management of a severe paradoxical reaction associated with combined treatment of Buruli ulcer and HIV coinfection. BMC Infect Dis 14:423. https://doi.org/10.1186/1471-2334-14-423

98. Johnson RC, Nackers F, Glynn JR et al (2008) Association of HIV infection and Mycobacterium ulcerans disease in Benin. AIDS 22:901-903. https://doi.org/10.1097/ QAD.0b013e3282f7690a

99. Toll A, Gallardo F, Ferran M et al (2005) Aggressive multifocal Buruli ulcer with associated osteomyelitis in an HIV-positive patient. Clin Exp Dermatol 30:649-651. https://doi. org/10.1111/j.1365-2230.2005.01892.x

100. Vincent QB, Ardant M-F, Marsollier L et al (2014) HIV infection and Buruli ulcer in Africa. Lancet Infect Dis 14:796-797. https://doi.org/10.1016/S1473-3099(14)70882-5

101. Prasad R (1993) Pulmonary sarcoidosis and chronic cutaneous atypical mycobacter ulcer. Aust Fam Physician 22:755-758

102. Martins TG, Trigo G, Fraga AG et al (2012) Corticosteroid-induced immunosuppression ultimately does not compromise the efficacy of antibiotherapy in murine Mycobacterium ulcerans infection. PLoS Negl Trop Dis 6:e1925. https://doi.org/10.1371/journal.pntd.0001925

103. Ogino S, King EE, Beck AH et al (2012) Interdisciplinary education to integrate pathology and epidemiology: towards molecular and population-level health science. Am J Epidemiol 176:659-667. https://doi.org/10.1093/aje/kws226

104. Jacobsen KH, Padgett JJ (2010) Risk factors for Mycobacterium ulcerans infection. Int J Infect Dis 14:e677-e681. https://doi.org/10.1016/j.ijid.2009.11.013

105. Amofah G, Bonsu F, Tetteh C et al (2002) Buruli ulcer in Ghana: results of a national case search. Emerg Infect Dis 8:167-170. https://doi.org/10.3201/eid0802.010119

106. Debacker M, Aguiar J, Steunou C et al (2004) Mycobacterium ulcerans disease: role of age and gender in incidence and morbidity. Trop Med Int Health 9:1297-1304. https://doi. org/10.1111/j.1365-3156.2004.01339.x

107. Debacker M, Portaels F, Aguiar J et al (2006) Risk factors for Buruli ulcer, Benin. Emerg Infect Dis 12:1325-1331. https://doi.org/10.3201/eid1209.050598

108. Landier J, Fontanet A, Texier G (2014) Defining and targeting high-risk populations in Buruli ulcer. Lancet Glob Health 2:e629. https://doi.org/10.1016/S2214-109X(14)70311-0

109. Tai AYC, Athan E, Friedman ND et al (2018) Increased severity and spread of Mycobacterium ulcerans, Southeastern Australia. Emerg Infect Dis 24:58. https://doi.org/10.3201/ eid2401.171070

110. The Uganda Buruli Group (1971) Epidemiology of Mycobacterium ulcerans infection (Buruli ulcer) at Kinyara, Uganda. Trans R Soc Trop Med Hyg 65:763-775

111. Vincent QB, Ardant M-F, Adeye A et al (2014) Clinical epidemiology of laboratoryconfirmed Buruli ulcer in Benin: a cohort study. Lancet Glob Health 2:e422-e430. https:// doi.org/10.1016/S2214-109X(14)70223-2

112. Bratschi MW, Bolz M, Minyem JC et al (2013) Geographic distribution, age pattern and sites of lesions in a cohort of Buruli ulcer patients from the Mapé Basin of Cameroon. PLoS Negl Trop Dis 7:e2252. https://doi.org/10.1371/journal.pntd.0002252

113. N'krumah RTAS, Koné B, Cissé G et al (2017) Characteristics and epidemiological profile of Buruli ulcer in the district of Tiassalé, south Côte d'Ivoire. Acta Trop 175:138-144. https:// doi.org/10.1016/j.actatropica.2016.12.023

114. Nhamoyebonde S, Leslie A (2014) Biological differences between the sexes and susceptibility to tuberculosis. J Infect Dis 209(Suppl 3):S100-S106. https://doi.org/10.1093/infdis/ jiu 147

115. Vesosky B, Turner J (2005) The influence of age on immunity to infection with Mycobacterium tuberculosis. Immunol Rev 205:229-243. https://doi.org/10.1111/j.0105-2896.2005.00257.x

116. Alcaïs A, Fieschi C, Abel L, Casanova J-L (2005) Tuberculosis in children and adults: two distinct genetic diseases. J Exp Med 202:1617-1621. https://doi.org/10.1084/jem.20052302 
117. Dreesman A, Corbière V, Dirix V et al (2017) Age-stratified T cell responses in children infected with Mycobacterium tuberculosis. Front Immunol 8:1059. https://doi.org/10.3389/ fimmu.2017.01059

118. Guerra-Laso JM, González-García S, González-Cortés C et al (2013) Macrophages from elders are more permissive to intracellular multiplication of Mycobacterium tuberculosis. Age (Dordr) 35:1235-1250. https://doi.org/10.1007/s11357-012-9451-5

119. Guzzetta G, Kirschner D (2013) The roles of immune memory and aging in protective immunity and endogenous reactivation of tuberculosis. PLoS One 8:e60425. https://doi. org/10.1371/journal.pone.0060425

120. Harari A, Rozot V, Bellutti Enders F et al (2011) Dominant TNF- $\alpha+$ Mycobacterium tuberculosis-specific $\mathrm{CD} 4+\mathrm{T}$ cell responses discriminate between latent infection and active disease. Nat Med 17:372-376. https://doi.org/10.1038/nm.2299

121. Orme IM (1987) Aging and immunity to tuberculosis: increased susceptibility of old mice reflects a decreased capacity to generate mediator T lymphocytes. J Immunol 138:4414-4418

122. Klein SL, Flanagan KL (2016) Sex differences in immune responses. Nat Rev Immunol 16:626-638. https://doi.org/10.1038/nri.2016.90

123. Lamberts SW, van den Beld AW, van der Lely AJ (1997) The endocrinology of aging. Science 278:419-424

124. Giefing-Kröll C, Berger P, Lepperdinger G, Grubeck-Loebenstein B (2015) How sex and age affect immune responses, susceptibility to infections, and response to vaccination. Aging Cell 14:309-321. https://doi.org/10.1111/acel.12326

125. Yamamoto Y, Saito H, Setogawa T, Tomioka H (1991) Sex differences in host resistance to Mycobacterium marinum infection in mice. Infect Immun 59:4089-4096

126. Sanchez AM, Flamini MI, Baldacci C et al (2010) Estrogen receptor-alpha promotes breast cancer cell motility and invasion via focal adhesion kinase and N-WASP. Mol Endocrinol 24:2114-2125. https://doi.org/10.1210/me.2010-0252

127. Barker DJ (1972) The distribution of Buruli disease in Uganda. Trans R Soc Trop Med Hyg 66:867-874

128. Raghunathan PL, Whitney EAS, Asamoa K et al (2005) Risk factors for Buruli ulcer disease (Mycobacterium ulcerans infection): results from a case-control study in Ghana. Clin Infect Dis 40:1445-1453. https://doi.org/10.1086/429623

129. Ampah KA, Asare P, Binnah DD-G et al (2016) Burden and historical trend of Buruli ulcer prevalence in selected communities along the Offin River of Ghana. PLoS Negl Trop Dis 10:e0004603. https://doi.org/10.1371/journal.pntd.0004603

130. Johnson PDR, Lavender CJ (2009) Correlation between Buruli ulcer and vector-borne notifiable diseases, Victoria, Australia. Emerg Infect Dis 15:614-615. https://doi.org/10.3201/ eid1504.081162

131. Marsollier L, Deniaux E, Brodin P et al (2007) Protection against Mycobacterium ulcerans lesion development by exposure to aquatic insect saliva. PLoS Med 4:e64. https://doi. org/10.1371/journal.pmed.0040064

132. Tian RDB, Lepidi H, Nappez C, Drancourt M (2016) Experimental survival of Mycobacterium ulcerans in watery soil, a potential source of Buruli ulcer. Am J Trop Med Hyg 94:89-92. https://doi.org/10.4269/ajtmh.15-0568

133. Tomczyk S, Deribe K, Brooker SJ et al (2014) Association between footwear use and neglected tropical diseases: a systematic review and meta-analysis. PLoS Negl Trop Dis 8:e3285. https://doi.org/10.1371/journal.pntd.0003285

134. Miyamoto Y, Komine M, Takatsuka Y et al (2014) Two cases of Buruli ulcer in Japanese brothers. J Dermatol 41:771-772. https://doi.org/10.1111/1346-8138.12540

135. O'Brien DP, Wynne JW, Buultjens AH et al (2017) Exposure risk for infection and lack of human-to-human transmission of Mycobacterium ulcerans disease, Australia. Emerg Infect Dis 23:837-840. https://doi.org/10.3201/eid2305.160809

136. Ohtsuka M, Kikuchi N, Yamamoto T et al (2014) Buruli ulcer caused by Mycobacterium ulcerans subsp shinshuense: a rare case of familial concurrent occurrence and detection of insertion sequence 2404 in Japan. JAMA Dermatol 150:64-67. https://doi.org/10.1001/jamadermatol.2013.6816 
137. Sopoh GE, Barogui YT, Johnson RC et al (2010) Family relationship, water contact and occurrence of Buruli ulcer in Benin. PLoS Negl Trop Dis 4:e746. https://doi.org/10.1371/ journal.pntd.0000746

138. Debacker M, Zinsou C, Aguiar J et al (2002) Mycobacterium ulcerans disease (Buruli ulcer) following human bite. Lancet 360:1830. https://doi.org/10.1016/S0140-6736(02)11771-5

139. Debacker M, Zinsou C, Aguiar J et al (2003) First case of Mycobacterium ulcerans disease (Buruli ulcer) following a human bite. Clin Infect Dis 36:e67-e68. https://doi. org/10.1086/367660

140. Capela C, Sopoh GE, Houezo JG et al (2015) Clinical epidemiology of Buruli ulcer from Benin (2005-2013): effect of time-delay to diagnosis on clinical forms and severe phenotypes. PLoS Negl Trop Dis 9:e0004005. https://doi.org/10.1371/journal.pntd.0004005

141. Bibert S, Bratschi MW, Aboagye SY et al (2017) Susceptibility to Mycobacterium ulcerans disease (Buruli ulcer) is associated with IFNG and iNOS gene polymorphisms. Front Microbiol 8:1903. https://doi.org/10.3389/fmicb.2017.01903

142. Goswami T, Bhattacharjee A, Babal P et al (2001) Natural-resistance-associated macrophage protein 1 is an $\mathrm{H}+/$ bivalent cation antiporter. Biochem J 354:511-519

143. Stienstra Y, van der Werf TS, Oosterom E et al (2006) Susceptibility to Buruli ulcer is associated with the SLC11A1 (NRAMP1) D543N polymorphism. Genes Immun 7:185-189. https://doi.org/10.1038/sj.gene.6364281

144. Capela C, Dossou AD, Silva-Gomes R et al (2016) Genetic variation in autophagy-related genes influences the risk and phenotype of Buruli ulcer. PLoS Negl Trop Dis 10:e0004671. https://doi.org/10.1371/journal.pntd.0004671

145. Juárez E, Carranza C, Hernández-Sánchez F et al (2012) NOD2 enhances the innate response of alveolar macrophages to Mycobacterium tuberculosis in humans. Eur J Immunol 42:880 889. https://doi.org/10.1002/eji.201142105

146. Manzanillo PS, Ayres JS, Watson RO et al (2013) The ubiquitin ligase parkin mediates resistance to intracellular pathogens. Nature 501:512-516. https://doi.org/10.1038/nature12566

147. Lewis CM (2002) Genetic association studies: design, analysis and interpretation. Brief Bioinform 3:146-153

148. Fletcher HA (2016) Sleeping beauty and the story of the Bacille Calmette-Guérin vaccine. MBio 7:e01370-e01316. https://doi.org/10.1128/mBio.01370-16

149. Nackers F, Dramaix M, Johnson RC et al (2006) BCG vaccine effectiveness against Buruli ulcer: a case-control study in Benin. Am J Trop Med Hyg 75:768-774

150. Phillips RO, Phanzu DM, Beissner M et al (2015) Effectiveness of routine BCG vaccination on Buruli ulcer disease: a case-control study in the Democratic Republic of Congo, Ghana and Togo. PLoS Negl Trop Dis 9:e3457. https://doi.org/10.1371/journal.pntd.0003457

151. Pommelet V, Vincent QB, Ardant M-F et al (2014) Findings in patients from Benin with osteomyelitis and polymerase chain reaction-confirmed Mycobacterium ulcerans infection. Clin Infect Dis 59:1256-1264. https://doi.org/10.1093/cid/ciu584

152. Portaels F, Aguiar J, Debacker M et al (2002) Prophylactic effect of Mycobacterium bovis BCG vaccination against osteomyelitis in children with Mycobacterium ulcerans disease (Buruli ulcer). Clin Diagn Lab Immunol 9:1389-1391

153. Portaels F, Aguiar J, Debacker M et al (2004) Mycobacterium bovis BCG vaccination as prophylaxis against Mycobacterium ulcerans osteomyelitis in Buruli ulcer disease. Infect Immun 72:62-65

154. Smith PG, Revill WD, Lukwago E, Rykushin YP (1976) The protective effect of BCG against Mycobacterium ulcerans disease: a controlled trial in an endemic area of Uganda. Trans $\mathrm{R}$ Soc Trop Med Hyg 70:449-457

155. The Uganda Buruli Group (1969) BCG vaccination against Mycobacterium ulcerans infection (Buruli ulcer). First results of a trial in Uganda. Lancet 1:111-115

156. Fenner F (1957) Homologous and heterologous immunity in infections of mice with Mycobacterium ulcerans and Mycobacterium balnei. Am Rev Tuberc 76:76-89

157. Converse PJ, Almeida DV, Nuermberger EL, Grosset JH (2011) BCG-mediated protection against Mycobacterium ulcerans infection in the mouse. PLoS Negl Trop Dis 5:e985. https:// doi.org/10.1371/journal.pntd.0000985 
158. Tanghe A, Adnet P-Y, Gartner T, Huygen K (2007) A booster vaccination with Mycobacterium bovis BCG does not increase the protective effect of the vaccine against experimental Mycobacterium ulcerans infection in mice. Infect Immun 75:2642-2644. https://doi. org/10.1128/IAI.01622-06

159. Watanabe M, Nakamura H, Nabekura R et al (2015) Protective effect of a dewaxed wholecell vaccine against Mycobacterium ulcerans infection in mice. Vaccine 33:2232-2239. https://doi.org/10.1016/j.vaccine.2015.03.046

160. Bolz M, Bénard A, Dreyer AM et al (2016) Vaccination with the surface proteins MUL_2232 and MUL_3720 of Mycobacterium ulcerans induces antibodies but fails to provide protection against Buruli ulcer. PLoS Negl Trop Dis 10:e0004431. https://doi.org/10.1371/journal. pntd.0004431

161. Bolz M, Kerber S, Zimmer G, Pluschke G (2015) Use of recombinant virus replicon particles for vaccination against Mycobacterium ulcerans disease. PLoS Neg1 Trop Dis 9:e0004011. https://doi.org/10.1371/journal.pntd.0004011

162. Geroult S, Phillips RO, Demangel C (2014) Adhesion of the ulcerative pathogen Mycobacterium ulcerans to DACC-coated dressings. J Wound Care 23:417-418, 422-424. https://doi.org/10.12968/jowc.2014.23.8.417

163. Tanghe A, Content J, Van Vooren JP et al (2001) Protective efficacy of a DNA vaccine encoding antigen 85A from Mycobacterium bovis BCG against Buruli ulcer. Infect Immun 69:5403-5411

164. Tanghe A, Dangy J-P, Pluschke G, Huygen K (2008) Improved protective efficacy of a speciesspecific DNA vaccine encoding mycolyl-transferase Ag85A from Mycobacterium ulcerans by homologous protein boosting. PLoS Negl Trop Dis 2:e199. https://doi.org/10.1371/journal. pntd.0000199

165. Hart BE, Hale LP, Lee S (2015) Recombinant BCG expressing Mycobacterium ulcerans Ag85A imparts enhanced protection against experimental Buruli ulcer. PLoS Negl Trop Dis 9:e0004046. https://doi.org/10.1371/journal.pntd.0004046

166. Hart BE, Lee S (2016) Overexpression of a Mycobacterium ulcerans Ag85B-EsxH fusion protein in recombinant BCG improves experimental Buruli ulcer vaccine efficacy. PLoS Negl Trop Dis 10:e0005229. https://doi.org/10.1371/journal.pntd.0005229

167. Coutanceau E, Legras P, Marsollier L et al (2006) Immunogenicity of Mycobacterium ulcerans Hsp65 and protective efficacy of a Mycobacterium leprae Hsp65-based DNA vaccine against Buruli ulcer. Microbes Infect 8:2075-2081. https://doi.org/10.1016/j.micinf.2006.03.009

168. Roupie V, Pidot SJ, Einarsdottir T et al (2014) Analysis of the vaccine potential of plasmid DNA encoding nine mycolactone polyketide synthase domains in Mycobacterium ulcerans infected mice. PLoS Negl Trop Dis 8:e2604. https://doi.org/10.1371/journal.pntd.0002604

169. Butt AM, Nasrullah I, Tahir S, Tong Y (2012) Comparative genomics analysis of Mycobacterium ulcerans for the identification of putative essential genes and therapeutic candidates. PLoS One 7:e43080. https://doi.org/10.1371/journal.pone.0043080

170. Sarfo FS, Phillips RO, Ampadu E et al (2009) Dynamics of the cytokine response to Mycobacterium ulcerans during antibiotic treatment for M. ulcerans disease (Buruli ulcer) in humans. Clin Vaccine Immunol 16:61-65. https://doi.org/10.1128/CVI.00235-08

171. Trigo G, Martins TG, Fraga AG et al (2013) Phage therapy is effective against infection by Mycobacterium ulcerans in a murine footpad model. PLoS Negl Trop Dis 7:e2183. https:// doi.org/10.1371/journal.pntd.0002183

172. Huygen K (2003) Prospects for vaccine development against Buruli disease. Expert Rev Vaccines 2:561-569. https://doi.org/10.1586/14760584.2.4.561

173. Dangy J-P, Scherr N, Gersbach P et al (2016) Antibody-mediated neutralization of the exotoxin mycolactone, the main virulence factor produced by Mycobacterium ulcerans. PLoS Negl Trop Dis 10:e0004808. https://doi.org/10.1371/journal.pntd.0004808

174. Bolz M, Ruggli N, Borel N et al (2016) Local cellular immune responses and pathogenesis of Buruli ulcer lesions in the experimental Mycobacterium ulcerans pig infection model. PLoS Negl Trop Dis 10:e0004678. https://doi.org/10.1371/journal.pntd.0004678 
175. Bolz M, Ruggli N, Ruf M-T et al (2014) Experimental infection of the pig with Mycobacterium ulcerans: a novel model for studying the pathogenesis of Buruli ulcer disease. PLoS Negl Trop Dis 8:e2968. https://doi.org/10.1371/journal.pntd.0002968

176. Clancey JK (1964) Mycobacterial skin ulcers in Uganda: description of a new Mycobacterium (Mycobacterium Buruli). J Pathol Bacteriol 88:175-187

177. Walsh DS, Cruz ECD, Abalos RM et al (2007) Clinical and histologic features of skin lesions in a cynomolgus monkey experimentally infected with Mycobacterium ulcerans (Buruli ulcer) by intradermal inoculation. Am J Trop Med Hyg 76:132-134

178. Manna V, Bem J, Marks R (1982) An animal model for chronic ulceration. Br J Dermatol 106:169-181

179. Summerfield A, Meurens F, Ricklin ME (2015) The immunology of the porcine skin and its value as a model for human skin. Mol Immunol 66:14-21. https://doi.org/10.1016/j. molimm.2014.10.023

180. Beissner M, Piten E, Maman I et al (2012) Spontaneous clearance of a secondary Buruli ulcer lesion emerging ten months after completion of chemotherapy-a case report from Togo. PLoS Negl Trop Dis 6:e1747. https://doi.org/10.1371/journal.pntd.0001747

181. Gordon CL, Buntine JA, Hayman JA et al (2011) Spontaneous clearance of Mycobacterium ulcerans in a case of Buruli ulcer. PLoS Negl Trop Dis 5:e1290. https://doi.org/10.1371/ journal.pntd.0001290

182. Marion E, Chauty A, Kempf M et al (2016) Clinical features of spontaneous partial healing during Mycobacterium ulcerans infection. Open Forum Infect Dis 3:ofw013. https://doi. org/10.1093/ofid/ofw013

183. Revill WD, Morrow RH, Pike MC, Ateng J (1973) A controlled trial of the treatment of Mycobacterium ulcerans infection with clofazimine. Lancet 2:873-877

184. Silva-Gomes R, Marcq E, Trigo G et al (2015) Spontaneous healing of Mycobacterium ulcerans lesions in the Guinea Pig model. PLoS Negl Trop Dis 9:e0004265. https://doi. org/10.1371/journal.pntd.0004265

185. Deshayes C,Angala SK, Marion E et al (2013) Regulation of mycolactone, the Mycobacterium ulcerans toxin, depends on nutrient source. PLoS Negl Trop Dis 7:e2502. https://doi. org/10.1371/journal.pntd.0002502

Open Access This chapter is licensed under the terms of the Creative Commons Attribution 4.0 International License (http://creativecommons.org/licenses/by/4.0/), which permits use, sharing, adaptation, distribution and reproduction in any medium or format, as long as you give appropriate credit to the original author(s) and the source, provide a link to the Creative Commons license and indicate if changes were made.

The images or other third party material in this chapter are included in the chapter's Creative Commons license, unless indicated otherwise in a credit line to the material. If material is not included in the chapter's Creative Commons license and your intended use is not permitted by statutory regulation or exceeds the permitted use, you will need to obtain permission directly from the copyright holder.

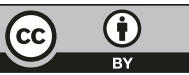

